\title{
Revolution in China
}

\section{Zum Toilettengang in die Chinesische Mauer}

\author{
So manchem Touristen bangte es vor den stillen öffentlichen Örtchen in China. Zu bekannt war deren \\ teilweise verheerender Zustand, bis die Regierung beschloss, ihren Besuchern saubere Toiletten zu \\ präsentieren - und eine Toilettenrevolution anzettelte.
}

G olden glänzt die Fassade im Sonnenlicht, der Bau thront imposant am Straßenrand. Gleich daneben: sauber bepflanzte Beete, hübsch geschnittene Hecken und zwei Statuen. Fünf Sterne verraten auf dem Schild neben der Tür, dass es sich hierbei um eine ganz besondere Anlage handelt.

Klingt wie die Beschreibung eines Luxus-Hotels? Nein, keinesfalls! Vielmehr ist der Bau in Form eines übergroßen Goldbarrens eine der ausgefallenen öffentlichen Toiletten in der nordwestchinesischen Stadt Linfen. Hier, in der Provinz Shanxi, lässt sich das Geschäft auch in einem Nachbau der Chinesischen Mauer verrichten - oder warum nicht einmal im filigran dekorierten Pavillon in traditionell chinesischer Architektur? Oder dem Nachbau des olympischen Schwimmbads, das ei- gentlich im 800 Kilometer entfernten Peking steht?

\section{Sterne ab sofort auch für Toiletten}

Seit 2008 hat die Stadt Linfen 60 kostenlose standardisierte öffentliche Toiletten gebaut - und das mit Bestmarken: 40 von ihnen tragen die höchste chinesische Auszeichnung für öffentliche Toiletten, fünf Sterne, zwölf dürfen sich über immerhin vier Sterne freuen.

Klingt wie ein Scherz, ist in China jedoch tatsächlich Realität: In der Volksrepublik gibt es Sterne nicht nur für Hotels, sondern auch für Toiletten. Denn seitdem das Land 2008 die Olympischen Spiele ausgetragen hat, forciert die Regierung die Verbesserung der öffentlichen Anlagen. Toiletten wurden renoviert und zusätzlich neue errichtet, in vielen Provinzen sogar offizielle Toiletten-Beauf-

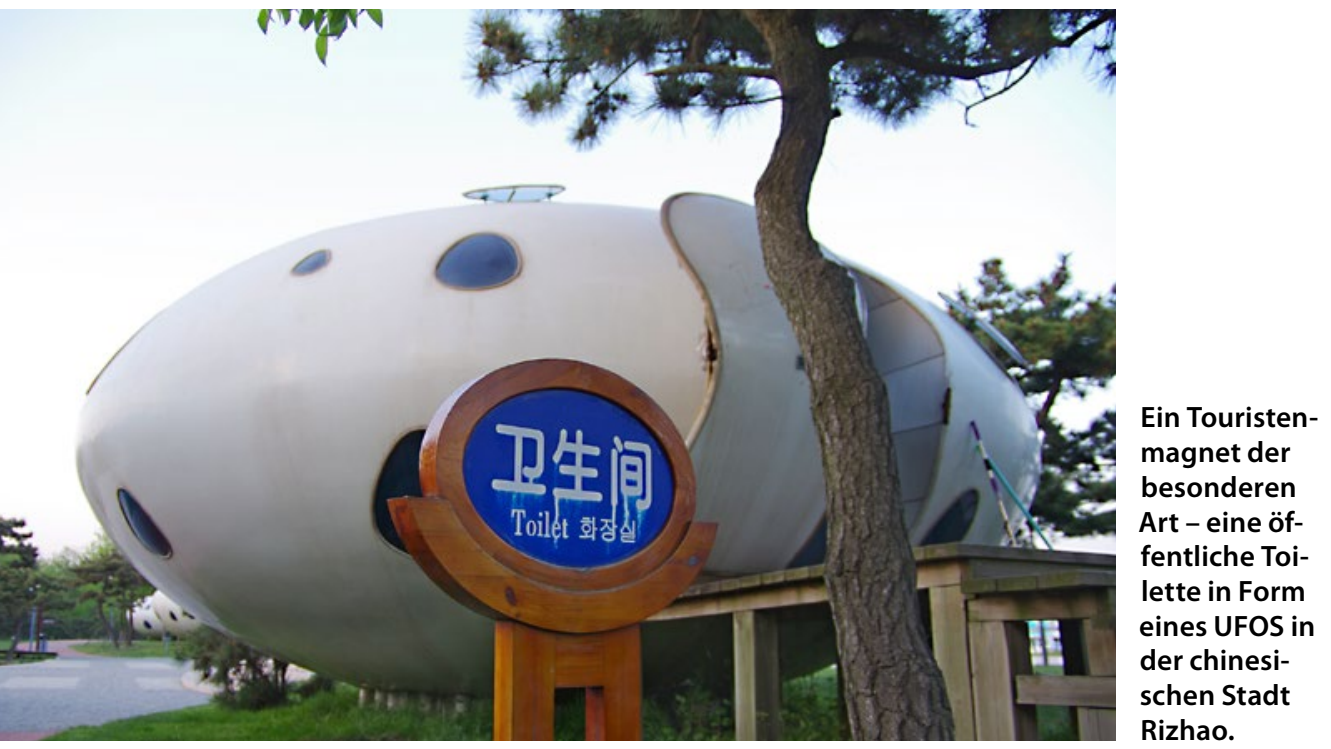

tragte ernannt. Beschleunigt wurden die Bemühungen dank der kurz darauffolgenden Expo 2010 in Schanghai.

Lange Zeit war in China nicht alles Gold, was glänzte: Die öffentlichen Toiletten waren auch in den wichtigsten Touristenstädten in solch schlechtem Zustand, dass internationale Besucher in Internetforen diskutierten, wie die Katastrophe überhaupt auszuhalten sei.

\section{Ungewöhnliche Hinweisschilder}

Durch die umfassenden Maßnahmen der Regierung hat sich die Situation in den vergangenen Jahren - zumindest in der Nähe großer touristischer Attraktionen - jedoch deutlich verbessert. Auch den Wünschen der westlichen Touristen hat man sich bei der Kloreform angenommen: So bieten heute viele, in jedem Fall aber alle Fünf-Sterne-Häuschen, auch „westliche" Toiletten. Traditionell sind in China Stehtoiletten üblich, die man auch aus anderen Erdteilen kennt. Für Chinesen bedeutet das eine Umstellung - so gibt es das weltweit womöglich einmalige Hinweisschild, das verbietet, sich mit den Füßen auf die Klobrille zu stellen und in die Hocke zu gehen. Daran müssen sich die Einheimischen gewöhnen - denn die Toilettenrevolution im Land geht weiter. Erst im Januar hat der Direktor des nationalen Tourismusamts Lin Jinzao angekündigt, bis 2017 für Touristen weitere Toiletten zu modernisieren. Im gesamten Land sollen dafür insgesamt 33.500 neue Toiletten gebaut und weitere 25.000 Toiletten erneuert werden. Sein Ziel? Alle Toiletten des Landes sollen zukünftig mindestens drei Sterne tragen!

Jana Kötter 